\title{
In vitro predatory activity of conidia of fungal isolates of the Duddingtonia flagrans on Angiostrongylus vasorum first-stage larvae
}

\author{
Fabio Ribeiro Braga ${ }^{[1]}$, Juliana Milani Araujo ${ }^{[1]}$, Jackson Victor de Araújo ${ }^{[1]}$, \\ Filippe Elias de Freitas Soares ${ }^{[2]}$, Alexandre de Oliveira Tavela ${ }^{[1]}$, Luiza Neme Frassy ${ }^{[1]}$, \\ Walter dos Santos Lima ${ }^{[3]}$ and Lanuze Rose Mozzer ${ }^{[3]}$
}

[1]. Departamento de Veterinária, Universidade Federal de Viçosa, Viçosa, MG. [2]. Departamento de Bioquímica e Biologia Molecular, Universidade Federal de Viçosa, Viçosa, MG. [3]. Departamento de Parasitologia Animal, Universidade Federal de Minas Gerais, Belo Horizonte, MG.

\begin{abstract}
Introduction: Angiostrongylus vasorum is a nematode that parasitizes molluscs, dogs, and even man. Methods: The objective was to evaluate the predatory activity of the conidia of two fungal isolates of Duddingtonia flagrans (AC001 and CG722) on first-stage larvae $\left(\mathrm{L}_{1}\right)$ of $A$. vasorum in laboratory conditions. Results: At the end of the experiment, there were significant reductions $(\mathrm{p}<0.01)$ of $74.5 \%$ and $63.2 \%$, on average, in the A. vasorum $\mathrm{L}_{1}$ recovered in the AC001 and CG722 treatment conditions, respectively. Conclusions: The two isolates of fungi were efficient in the capture and destruction of $A$. vasorum $\mathrm{L}_{1}$.
\end{abstract}

Keywords: Nematophagous fungi. Duddingtonia flagrans. Angiostrongylus vasorum.

Parasites of the genus Angiostrongylus (A. vasorum, A. cantonensis, and A. costaricensis) infect aquatic and terrestrial molluscs, which are the intermediate hosts. The life cycle of Angiostrongylus, although not understood completely, demonstrates a complexity of situations in which man may appear as a potential host ${ }^{1,2}$. According to Saeed et al. ${ }^{1}, A$. vasorum is a protostrongylid nematode with a biological cycle of the heteroxenic type, occurring in several regions where they were previously considered harmless ${ }^{3}$. Molluscs (intermediate hosts) become infected by ingesting first-stage larvae $\left(\mathrm{L}_{1}\right)$ of the parasite left in the feces of infected definitive hosts (dogs and wild canids). The larvae go through two changes in the mollusc until the third evolutionary stage $\left(\mathrm{L}_{3}\right)$, when it becomes infectious to the definitive host ${ }^{4}$. Dogs infected with $A$. vasorum may have a variety of symptoms, including neurological ones ${ }^{5}$, that can have severe consequences. In addition, due to close contact of humans with pets, especially dogs, there is a possibility of human contamination with $A$. vasorum. Because of the medical importance of angiostrongyliasis in humans and animals, studies have been carried out to determine the efficacy of treatment with albendazole ${ }^{6}$. However, there are no officially approved drugs for the treatment of dogs with angiostrongyliasis ${ }^{7}$.

The use of nematophagous fungi and ovicidal predators can help in the environmental decontamination of infective forms (or eggs and larvae) of potentially zoonotic parasites and therefore reduce the recurrence of helminth infections ${ }^{8}$. Duddingtonia flagrans is considered the most promising nematode-trapping

Address to: Dr. Fabio Ribeiro Braga. Depto. de Veterinária/UFV.Av. Ph Rolfes s/n, 36570-000 Viçosa, MG, Brazil.

Phone: 5531 3899-1458

e-mail: fabioribeirobraga@hotmail.com

Received in 05/02/2011

Accepted in 30/09/2011 species in the control of nematodiasis in domestic animals due to its large chlamydospore production. In laboratory conditions, different fungal isolates of $D$. flagrans have previously been successfully utilized to control gastrointestinal nematodes in domestic animals, especially the isolates AC001 and CG722, $2^{90}$. However, this is the first report comparing the in vitro predatory activity of the conidia of different isolates of the fungus D. flagrans on first-stage $\left(\mathrm{L}_{1}\right)$ larvae of A. vasorum.

The objective of the present study was to evaluate the predatory activity of the conidia of two fungal isolates of $D$. flagrans (AC001 and CG722) on first-stage larvae ( $\left.\mathrm{L}_{1}\right)$ of $A$. vasorum in laboratory conditions.

Two isolates of the nematophagous fungus $D$. flagrans (AC001 and CG722) were used. These isolates were obtained from Brazilian agricultural soil. After growth of the isolates in $2 \%$ cornmeal agar, new culture disks $4 \mathrm{~mm}$ in diameter were transferred to $9 \mathrm{~cm}$-diameter Petri dishes containing $20 \mathrm{ml}$ of $2 \%$ water agar ( $2 \% \mathrm{WA})$. Then, for a period of 21 days, $1 \mathrm{ml}$ of distilled water containing 1,000 larvae of Panagrellus sp. was added daily to induce fungal conidia formation. When complete fungal development was observed, $5 \mathrm{ml}$ of distilled water were added to each Petri dish, and the conidial and mycelial fragments were removed using the technique described by Araújo et al. ${ }^{11}$. The suspension present in the plates was screened through a sieve attached to a plastic container to remove the mycelium fragments.

The strain used in the assays was originally isolated from feces of two naturally infected dogs from the Brazilian City of Caratinga in the State of Minas Gerais ${ }^{12}$. This strain had been maintained by successive passages in dogs. Feces of infected dogs were collected and placed in a modified Baermann funnel for $12 \mathrm{~h}$ for $\mathrm{L}_{1}$ recovery ${ }^{13}$. After this period, the tube was removed and centrifuged at $200 \times g$ for $2 \mathrm{~min}$. The supernatant 
was discarded, and the pellet containing A. vasorum $\mathrm{L}_{1}$ was resuspended in $5 \mathrm{ml}$ of $0.85 \%$ saline solution. The content was homogenized, and three $10 \mu \mathrm{l}$ samples were removed and distributed in $7.5 \times 2.5 \mathrm{~cm}$ glass slides. A count of the larvae was carried out under a stereomicroscope $(25 \times)$. The total larval number was estimated by a simple rule of three.

The predation test was conducted on the surface of the Petri dishes according to a modified technique previously described by Braga et al. ${ }^{8}$. Three groups were formed on $9 \mathrm{~cm}$-diameter Petri dishes containing $20 \mathrm{ml}$ of $2 \%$ WA: two treatment groups (AC001 and CG722) and one control group (without fungi). Six repetitions were made for each group. The Petri dishes were previously marked into $4 \mathrm{~mm}$-diameter fields. In the treated groups, each Petri dish contained $A$. vasorum $\mathrm{L}_{1}$ and 500 conidia of the fungal isolate AC001 or CG722 in $2 \%$ WA. Each Petri dish in the control group contained only $500 \mathrm{~L}_{1}$ in $2 \%$ WA. Every $24 \mathrm{~h}$ for 7 days, ten $4 \mathrm{~mm}$-diameter random fields on each plate in the treated and control groups were observed under an optical microscope at $10 \times$ magnification; the number of $\mathrm{L}_{1}$ that had not been preyed on was counted on each plate. At the end of the 7-day period, the non-predated $\mathrm{L}_{1}$ were recovered from the Petri dishes using the Baermann apparatus with water at $42^{\circ} \mathrm{C}$.

The data obtained were examined by analysis of variance at 1 and $5 \%$ probability levels using the BioEstat 3.0 software (Manuel Ayres, Brazil). The efficiency of the predation activity was evaluated using Tukey's test at the $1 \%$ probability level. The percentage reduction in the mean larval recovery was calculated by the following equation:

Reduction $(\%)=\left(\right.$ mean $\mathrm{L}_{1}$ recovery from control - mean $\mathrm{L}_{1}$ recovery from treatment $) \times 100$. Mean $\mathrm{L}_{1}$ recovery from control

In the present study, even with the administration of conidia, the fungus produced optimum results as early as in the first 24 hours of reading (Table 1). The mean number of A. vasorum $\mathrm{L}_{1}$ not preyed on per $4 \mathrm{~mm}$-diameter field in the control condition was significantly different $(\mathrm{p}<0.01)$ from that on the plates treated with the fungus D. flagrans (AC001 and CG722) throughout the experiment. In addition, there were typical fungal structures (conidia and traps) on the boards of the treated groups during the test. At the end of the experiment, the following A. vasorum $\mathrm{L}_{1}$ percentage reductions were observed: $74.5 \%$ for AC001 and 63.2\% for CG722 (Figure 1).

The linear regression coefficients calculated by the analysis of the mean number of $A$. vasorum $\mathrm{L}_{1}$ per $4 \mathrm{~mm}$-diameter field in the treated and control groups were: 0.21 (AC001), 0.17 (CG722), and 0.67 (control) (Figure 2).

It is estimated that close to 1 billion people are currently infected by geohelminths, mainly due to contact with common soil, indicating that this is an important route of human infection, which itself is associated with varied grave health consequences if left untreated. In addition, studies on parasites infesting domestic animals have provoked increasing interest due to the intimate relationship that exists between man and these animals, which may be a public health concern ${ }^{14}$.
TABLE 1 - Daily means and standard deviations of non-predated first-stage larvae $\left(L_{1}\right)$ of Angiostrongylus vasorum per $4 m m$-diameter field in $2 \%$ water agar for the group treated for seven days with the fungus Duddingtonia flagrans (AC001 and CG722) and for the control group (without fungi).

\begin{tabular}{lccc}
\hline & \multicolumn{3}{c}{ Treatments (means of non-predated $\mathrm{L}_{\mathbf{1}}$ ) } \\
\cline { 2 - 4 } Time (days) & AC001 & CG722 & Control \\
\hline 1 & $2.6^{\mathrm{a}} \pm 3.03$ & $2.5^{\mathrm{a}} \pm 2.1$ & $7.0^{\mathrm{b}} \pm 2.0$ \\
2 & $1.2^{\mathrm{a}} \pm 1.6$ & $1.3^{\mathrm{a}} \pm 1.7$ & $4.6^{\mathrm{b}} \pm 4.0$ \\
3 & $2.1^{\mathrm{a}} \pm 2.8$ & $1.4^{\mathrm{a}} \pm 1.7$ & $3.9^{\mathrm{b}} \pm 3.0$ \\
4 & $1.3^{\mathrm{a}} \pm 1.8$ & $1.1^{\mathrm{a}} \pm 1.6$ & $3.0^{\mathrm{b}} \pm 3.1$ \\
5 & $1.2^{\mathrm{a}} \pm 1.1$ & $1.5^{\mathrm{a}} \pm 2.0$ & $2.5^{\mathrm{b}} \pm 3.2$ \\
6 & $1.2^{\mathrm{a}} \pm 1.3$ & $1.4^{\mathrm{a}} \pm 2.1$ & $2.8^{\mathrm{b}} \pm 2.5$ \\
7 & $0.9^{\mathrm{a}} \pm 1.2$ & $0.8^{\mathrm{a}} \pm 1.1$ & $2.4^{\mathrm{b}} \pm 2.2$ \\
\hline
\end{tabular}

AC001: Duddingtonia flagrans; CG722: Duddingtonia flagrans.

Means with a superscript letter indicate that the lines are not statistically different $(\mathrm{p}>0.01)$, Tukey's test.

The genera Ancylostoma and Toxocara, which are parasites of dogs and cats, and possibly the species $A$. vasorum stand out among helminths with zoonotic potential. Besides showing medical-veterinary importance, $A$. vasorum as a cardiopulmonary parasite of domestic and wild dogs requires special attention and investigation also because it can infect humans as well ${ }^{6,14}$. Few studies have mentioned the in vitro predatory activity of different nematophagous fungi on larvae of nematode parasites of dogs.

In the present study, the isolate CG722 demonstrated a mean value of 0.8 in relation to viable $\mathrm{L}_{1}$ in the treated Petri dishes at the end of the 7-day period. This result is concordant with Campos et al. ${ }^{9}$, who, using the same isolate (CG722) preying on $\mathrm{L}_{3}$ of Strongiloydes papillosus, demonstrated a mean of 10.41 in vitro at the end of 7 days. However, the changes observed here may have occurred as a result of various factors. According to Mendoza De Gives et al. ${ }^{15}$, the composition of the cuticle of nematodes can be a determining factor in the ability of fungi to prey on the nematodes. Also, antigenic variations in different nematodes or in the fungal isolate used may

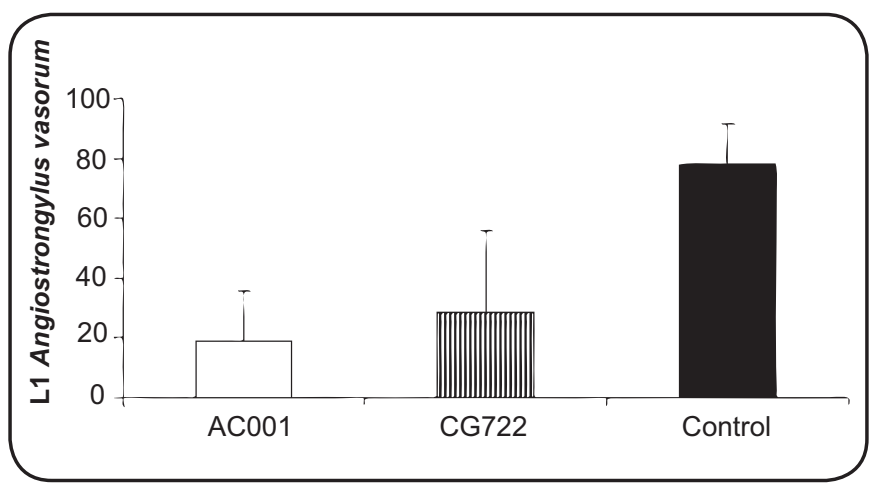

FIGURE 1 - Means and standard deviations (bars) of infective non-predated Angiostrongylus vasorum larvae recovered from $2 \%$ water-agar plates by the Baermann method on the seventh day of treatment with the following fungal isolates: Duddingtonia flagrans (AC001 and CG722) and control group (without fungi).

The asterisk denotes a significant difference $(\mathrm{p}<0.05)$ between the fungus-treated group and the control; Tukey's test at $1 \%$ probability level. 


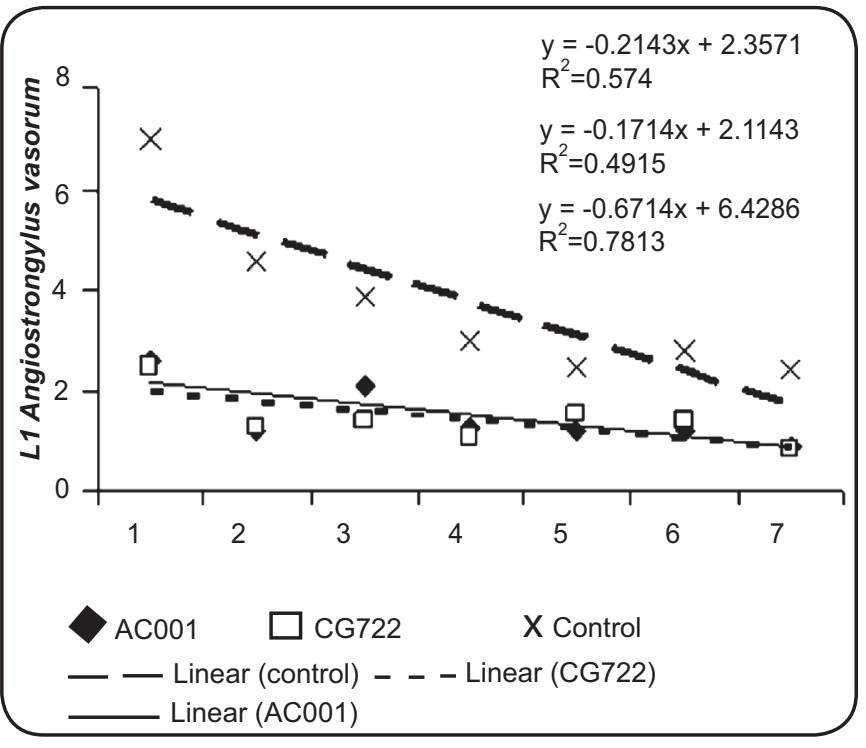

FIGURE 2 - Linear regression curves calculated using the mean Angiostrongylus vasorum larvae $\left(L_{1}\right)$ per $4 m m$-diameter field for the group treated with the fungus Duddingtonia flagrans (AC001 and CG722) and the control group (without fungi) as a function of time (1 to 7 days).

influence the rate of predation. Braga et al. ${ }^{10}$ demonstrated that AC001 grown in Petri dishes containing a solid culture (2\% WA) did prey on and consequently destroyed $80.3 \%$ of $A$. vasorum $\mathrm{L}_{1}$ at the end of 7 days. However, comparing this predatory activity with the observation in the present study, it can be noted that the efficiency $(74.5 \%)$ in this same strain was similar since the predation of larvae occurred after $24 \mathrm{~h}$. In this study, there was no statistically significant difference in the predatory ability of isolates of $D$. flagrans, as evidenced by the number of $A$. vasorum larvae recovered from the plates with the strains CG722 and AC001. However, differences in the inter- and intraspecific activity of predatory nematophagous fungi are common and have been observed in experiments with other fungal isolates ${ }^{11}$.

The negative coefficients of correlation indicate a downward behavior of the regression curves for the treatments with the fungal isolates AC001 (0.21) and CG722 (0.17). This was caused by the reduction in the mean numbers of non-predated A. vasorum $\mathrm{L}_{1}$ per $4 \mathrm{~mm}$-diameter field during the experimental assay, mainly due to the capture of $\mathrm{L}_{1}$ in fungal traps. The reduction in the number of $\mathrm{L}_{1}$ per $4 \mathrm{~mm}$-diameter field in the control group during the study, however, was caused by the migration of larvae to the periphery of the Petri dishes, where the moisture level was higher. This finding was also reported by Araújo et al. ${ }^{15}$, who carried out in vitro tests in Petri dishes. The results of this study confirm previous works on the efficiency of $D$. flagrans in the control of larvae of nematode parasites of dogs. As the larvae are free in the environment, there exists the possibility of human infection since other parasites of the genus Angiostrongylus have been proven to be zoonotic ${ }^{2}$. In this context, we suggest the application of nematophagous fungi, especially any of the isolates of the species D. flagrans tested (AC001, CG722, and CG768), that are capable of destroying $\mathrm{L}_{3}$ of potentially zoonotic gastrointestinal nematode parasites.
In conclusion, the fungal conidia of $D$. flagrans (AC001 and CG722) have predatory activity on first-stage larvae of $A$. vasorum and could be used as a possible alternative method of biological control of $A$. vasorum larvae.

\section{CONFLICT OF INTEREST}

The authors declare that there is no conflict of interest.

\section{FINANCIAL SUPPORT}

$\mathrm{CNPq}$ (Conselho Nacional de Desenvolvimento Cientifico e Tecnológico; National Council of Technological and Scientific Development), FAPEMIG (Fundação de Amparo à Pesquisa do Estado de Minas Gerais; Research Support Foundation of Minas Gerais), and CAPES (Coordenação de Aperfeiçoamento de Pessoal de Nivel Superior; Coordination for Improvement of Higher Education Personnel).

\section{REFERENCES}

1. Saeed I, Maddox-Hyttel C, Monrad J, Kapel CMO. Helminths of red fox (Vulpes vulpes) in Denmark. Vet Parasitol 2006; 139:168-179.

2. Caldeira RL, Carvalho OS, Mendonça CLFG, Graeff-Teixeira C, Silva MCF, Ben R, et al. Molecular differentiation of Angiostrongylus costaricensis, A. cantonensis, and A. vasorum by polymerase chain reaction-restriction fragment length polymorphism. Mem Inst Oswald Cruz 2003; 98:1039-1043.

3. Morgan ER, Shaw SE, Brennan SF, De Waal TD, Jones BR, Mulcahy G. Angiostrongylus vasorum: a real heartbreaker. Trends Parasitol 2005; 21:49-51.

4. Guilhon J. Role des limacidés dans le cycle évolutif d'Angiostrongylus vasorum (Baillet, 1866). CR Acad Sci 1960; 251:2252-2253.

5. Cury MC, Guimarães MP, Lima WS, Caldeira MCM, Couto TR, Murta K, et al. Biochemical serum profiles in dogs experimentally infected with Angiostrongylus vasorum (Baillet, 1866). Vet Parasitol 2002; 128:121-127.

6. Eckert J, Lämmler G. Angiostrongylose bei Mensch und Tier. Parasitol Res 1972; 39:303-322.

7. Conboy GA. Angiostrongylus vasorum in dogs in Atlantic Canada and their treatment with milbemycin oxime. Vet Rec 2004; 155:16-18.

8. Braga FR, Silva AR, Araujo JM, Carvalho RO, Araujo JV, Frassy LN. Atividade predatória dos fungos nematófagos Duddingtonia flagrans, Monacrosporium thaumasium e Artrobotrys robusta sobre larvas infectantes de Strongyloides stercoralis. Rev Soc Bras Med Trop 2010; 43:588-590.

9. Campos AK, Araújo JV, Guimarães MP. Interaction between the nematophagous fungus Duddingtonia flagrans and infective larvae of Haemonchus contortus (Nematoda: Trichostrongyloidea). J Helminthol 2008; 82:337-341.

10. Braga FR, Carvalho RO, Araujo JM, Silva AR, Araújo JV, Lima WS, et al. Predatory activity of the fungi Duddingtonia flagrans, Monacrosporium thaumasium, Monacrosporium sinense and Arthrobotrys robusta on Angiostrongylus vasorum first-stage larvae. J Helminthol 2009; 83:303-308.

11. Araújo JV, Santos MA, Ferraz S, Maia AS. Antagonistic effect of predacious Arthrobotrys fungi on infective Haemonchus placei larvae. J Helminthol 1993; 67:136-138.

12. Lima WS, Costa HMA, Guimarães MP, Leite ACR. Angiostrongylus vasorum (Baillet, 1866) Nematoda: Prothostrongylidae em cães de Minas Gerais, Brasil. Mem Inst Oswaldo Cruz 1985; 80:233-235.

13. Barçante JMP, Barçante TA, Dias SRC, Vieira LQ, Lima WS, Negrão-Corrêa D. A method to obtain axenic Angiostrongylus vasorum first-stage larvae from dog feces. Parasitol Res 2003; 89:89-93.

14. Patteson MW, Gibbs C, Wotton PR, Day MJ. Angiostrongylus vasorum infection in seven dogs. Vet Rec 1993; 4:565-570.

15. Mendoza De Gives P, Davies KG, Clark SJ, Behnke JM. Predatory behavior of trapping fungi against srf mutants of Caenorhabditis elegans and different plant and animal parasitic nematodes. Parasitology 1999; 119:95-104. 